\title{
JOVENS NEGROS LGBT'S NO AMBIENTE ESCOLAR: COMO TRABALHAR A SEXUALIDADE NAS ESCOLAS NA PERSPECTIVA DAS RELAÇÕES ÉTNICO- RACIAIS?
}

\section{LGBT's black young people in the school environment: how to teach sexuality in schools in the perspective of ethnic-racial relations?}

\author{
Hiram Campos Rodrigues - UFSB/Brasil
}

\begin{abstract}
RESUMO: Este artigo pretende descrever sobre a sexualidade no ambiente escolar e propor uma reflexão, com o intuito de conscientizar educadores, a respeito do tema da sexualidade na perspectiva das relações étnico-raciais/lésbicas, gays, bissexuais, travestis transexuais ou trensgênicos (LGBT's). Para isso, realizou um levantamento de referencial teórico, análise de publicações e vídeos disponíveis nas redes sociais sobre os jovens negros LGBT's no ambiente escolar e foi disponibilizado um questionário em plataforma digital, algumas das respostas obtidas foram apresentadas e analisadas com base em autores e suas proposições a respeito do tema abordado. Assim, enfoca a importância da utilização do espaço escolar na conscientização e formação de sujeitos acerca das relações étnico-raciais, do reconhecimento de gêneros e identidades. E também os efeitos de práticas pedagógicas reforçadoras de estereótipos heteronormativos e discriminatórios em jovens, que não se enquadram nos padrões de sexualidade ditados pela sociedade hegemônica, como é o caso dos negros LGBT's.
\end{abstract}

Palavras-chave: LGBT’s. Sexualidade. Relações étnico-raciais. Sociedade.

ABSTRACT: This article aims to describe sexuality in the school environment and to propose a reflection, in order to raise educators' awareness about the theme of sexuality from the perspective of ethnic-racial / lesbian, gay, bisexual, transgender or transgender (LGBT) transvestites. For this, it conducted a survey of the theoretical framework, analysis of publications and videos available on social networks about young black LGBT's in the school environment and was made available a digital platform questionnaire, some of the answers obtained were presented and analyzed based on authors and their propositions about the topic addressed. Thus, it focuses on the importance of using the school space in the awareness and formation of subjects about ethnic-racial relations, recognition of gender and identities. And also the effects of pedagogical practices that reinforce heteronormative and discriminatory stereotypes in young people, which do not fit the standards of sexuality dictated by hegemonic society, as is the case with LGBT blacks.

Keywords: LGBT's. Sexuality. Ethnic-racial relations. Society.

Educação, Psicologia e Interfaces, Volume 2, Número 2, p. 86-96, Maio/Agosto, 2018. 
Jovens negros lgbt's no ambiente escolar: como trabalhar a sexualidade nas escolas na perspectiva das relações étnico-raciais?

\section{INTRODUÇÃO}

É inegável que em escolas e outras instituições são verificados discursos hegemônicos sobre gêneros, sexualidades, etnias e raças. Por isso, torna-se importante refletir com os profissionais da educação para se buscar uma compreensão analítica sobre os discursos e práticas relacionados com estas temáticas no ambiente escolar e suas implicações na sociedade para que novas práticas pedagógicas possam ser pensadas e elaboradas no sentido de respeitar a diversidade nos espaço educacionais.

A escola é um espaço para discussão das temáticas de gênero, sexualidade e relações étnico-raciais, pois atua na formação de sujeitos e suas identidades de acordo com os códigos e regras estabelecidos social e culturalmente, além de contestar ou conservar valores.

É importante que os alunos saibam os significados das palavras gênero, raça, etnia e o que elas representam na vivência de cada um. É necessário também é abordar a relação entre a aparência das pessoas, a orientação sexual, a cor da sua pele, com a discriminação e exclusão sofridas por alguns jovens que naõ se encaixam nos padrões mais "aceitos" e impostos pela sociedade.

Segundo Weeks (1999), a sexualidade envolve uma série de crenças, comportamentos, relações e identidades socialmente construídas e historicamente modelas. A escola atua no reforço de crenças e comportamentos e, na maioria das vezes, fortalece ideias heterossexitas, racistas e que podem gerar inúmeros problemas nas vidas dos que não se encaixam em padrões pré-determinados de cor, sexualidade e outros comportamentos.

É necessário estarmos atentos, como educadores, a questões afetas ao gênero e á sexualidade que são silenciadas ou referidas apenas a partir daquilo que é representado como sendo o normal, o desejável, o aceitável (GOELLNER, 2009). A questão da sexualidade e do gênero, também deve ser discutida atrelada à questão étnico-racial, já que vivemos em um país que objetifica a mulher negra e que preconceitua o homem negro homossexual que não atende ao imaginário do negro viril, forte e másculo.

Os estereótipos reforçados nas escolas excluem muitos sujeitos do ambiente escolar, seja pela cor da pele, condição financeira ou sexual, e faz-se necessária uma intervenção para que se desenvolvem reflexões que extrapolem o determinismo biológico e o reducionismo binário de gênero e a manutenção do preconceito nas práticas das 
escolas brasileiras.

A nossa educação sexual escolar geralmente aborda os fenômenos puramente biológicos estudando características fisiológicas e anatômicas envolvidas com a expressão da sexualidade humana, no entanto, Segundo Souza (2007), a mesma deixa de abordar aspectos sócio/histórico/culturais que se inscrevem constantemente nas experiências dos indivíduos.

Uma das primeiras dificuldades para a identificação da discriminação no ambiente escolar é o fato da mesma ser, constantemente, negada e muitas vezes ser considerada brincadeira "normal" entre colegas. As crianças acabam não enxergando suas atitudes na escola como racistas e os professors, em sua maioria, não possuem formação para trabalhar com os comportamentos de exclusão étnico-raciais ou de gênero.

Para Louro (2005, p. 86) "homens e mulheres não se constituem, apenas por sua identidade de gênero, mas também por sua identidade de classe, de raça, de etnia, de sexualidade, nacionalidade, idade... homens e mulheres são, ao mesmo tempo, muitas “coisas"'. É sobre esta perspectiva que vai além do biológico e engloba o olhar social e cultural das práticas pedagógicas que excluem jovens negros lésbicas, gays, bissexuais, travestis transexuais ou trensgênicos (LGBT's). Este arigo pretende descrever sobre a sexualidade no ambiente escolar e propor uma reflexão, com o intuito de conscientizar educadores, a respeito do tema da sexualidade na perspectiva das relações étnico-raciais e LGBT's.

\section{MATERIAL E MÉTODO}

Realizou-se um levantamento de referencial teórico, análise de publicações e vídeos disponíveis nas redes sociais sobre os jovens Negros LGBT's no ambiente escolar, visando discutir sobre as práticas pedagógicas voltadas para discussão do tema sexualidade nas escolas e também considerndo as relações étnico-raciais.

Além disso, foi disponibilizado um questionário em plataforma digital. As pesquntas realizadas feitas foram: durante o Ensino Médio, você já esteve envolvido em discriminação? Descreva a sua experiência com a discriminação contra jovens negros gays.Caso tenha respondido "Sim", a natureza do seu envolvimento foi como: autor, vítima, testemunha. Durante o tempo em que você sofreu discriminação (como vítima, autor, espectador, ou testemunha ocular), você pediu ajuda a seus professores ou a 
Jovens negros lgbt's no ambiente escolar: como trabalhar a sexualidade nas escolas na perspectiva das relações étnico-raciais?

administração de sua escola? Caso tenha respondido "Sim" na pergunta anterior, os (as) professores (as) e/ou administradores escola lhe ajudaram? Como? Caso tenha respondido "Não", em sua avaliação, por qual o motivo não lhe foi prestado ajuda? Os (as) professores (as) e administradores da escola onde você estuda (estudou) intervêm/interviam em casos de discriminação contra negros e gays ou qualquer outra forma manifesta de discriminação?

Algumas das respostas obtidas foram apresentadas na seção de resultados e discussão. Para a análise das mesmas recorreu-se a reflexão baseada em autores e suas proposições a respeito do tema abordado.

\section{RESULTADO E DISCUSSÃO}

Sabes-e que gênero, sexualidade, raça e etnia são temas discutidos e que estão relacionados as minorias, que têm em comum não o fato de expressarem um menor contingente populacional, mas, sim, de representarem valores que foram construídos ao longo da história, como antagônicos a valores expressos como superiores e desejáveis. Assim, a construção hegemônica do masculino é feita em oposição à constituição inferior do feminino, a do branco em oposição à do negro, e a do heterossexual em oposição à do homossexual (MOTTA, 2016).

Sobre o preconceito persistente em nossa sociedade, Grüner (2002) afirma que um postulado básico da teoria pós-colonial é que a conformação histórica de uma subjetividade colonialista por meio da cultura não é algo que tenha desaparecido com o colonialismo; pelo contrário é a condição fundante da persistência da subordinação cultural no pós-colonialismo.

Os LGBTs negros são habitantes de dois mundos distintos, que são, ao mesmo tempo, dois tabus da sociedade brasileira, a homossexualidade e a raça. Além de serem mundos tabus, são face de uma sociedade fraturada e descontínua para o homossexual negro que existe de formas diferentes em cada um deles. A negritude se constitui através da normalização do negro heterossexual, representado pela emblemática virilidade de sua força física, agressividade, violência, grande apetite sexual e pênis potente (ROSA, 2006).

\subsection{Descrição de alguns vídeos do youtube sobre sexualidade e questão étnico-racial}

Não se pode dissociar a discussão sobre sexualidade e juventude na escola sem abordar

a questão

étnico-racial.

No

vídeo 
https://www.youtube.com/watch?v=E86P8Hj9d4Q no youtube, no canal gupodoscinco.com, Lucas Brandão afirma que ninguém quer namorar com os gays negros. Segundo ele a solidão do gay e da lésbica negra é enorme. "A gente encontra alguém, fica com alguém mas a pessoa não querem nos assumir". "Corremos mais riscos de sofrer violência". "Sofremos por sermos gays e por sermos negros".

No canal Papo de Preta https://www.youtube.com/watch?v=hyJMV6rhVxI no youtube, a apresentadora relata o seguinte; "Eu tenho pesquisado sobre a homofobia e muito do que vejo são negros gays falando que não se sentem aceitos no meio LGBT por que existe um estereótipo desejável de pessoas brancas e não se sentem inseridos no movimento negro porque tem o padrão do homem negro". O convidado do canal Davidson Santos afirma que existe este afastamento, "o movimento LBBT em geral inconscientemente se recusa a entender a negritude como uma interseção dentro do movimento". O mesmo lembra que estamos falando de uma sociedade racista. "No movimento a gente quebra um padrão de virilidade que é esperado do negro, então suas discussões não tocam o suficiente para ser pauta".

Em outro canal disponível no youtube: https://www.youtube.com/watch?v=tMJoQJvOLNY, o jovem AD Junior, com o vídeo "Moonlight e solidão do negro gay" afirma que "a solidão do negro gay existe e é legitima”. Ele questiona a forma como tratamos o negro gay em nossa sociedade. Uma figura que é vista quase sempre como caricata e engraçada, mas quase nunca amada. $A D$ completa: "uma das primeiras vitimas de zombaria online foi a Layla Domique. Preta, feia e engraçada eram os comentários mais generosos que se faziam sobre ela. O Brasil aprendeu a zombar da figura da bicha preta nos anos 90 quando Renato Aragão introduziu nos trapalhões a figura caricata interpretada pelo saudoso Jorge Lafond. A realidade é que os negros gays são engraçados mas são ao mesmo tempo os menos desejados".

Ainda segundo $\mathrm{AD}$ “o negro gay retinto geralmente é o que sofre com a solidão e a desvalorização. Moonglight foi o grande vencedor do Oscar e nos trouxe a solidão do negro para o debate. Ele apresenta o silencio do negro acuado pelas circunstâncias de uma sexualidade que ele não pode mudar. O clamor como negros e gays vai além da objetificação do corpo. Os negros, pretos, retintos são os mais pobres, mais caricaturados e os menos desejados, quando são gordos ou magros demais e 
Jovens negros lgbt's no ambiente escolar: como trabalhar a sexualidade nas escolas na perspectiva das relações étnico-raciais?

principalmente os afeminados. Na infância quando percebemos que não somos o 'negão de tirar o chapéu' passamos a ser motivo de piadas na escola e isso afeta nossa autoestima"

Ainda completa $\mathrm{AD}$ que "no mundo gay existe uma dupla moral para os negros: aquele que a sociedade vê como aceitável por puro colonialismo e o que é descartável e só serve para transar no escuro".

Casos como os abordados nos vídeos são reflexos da exclusão, da estigmatização e da inferiorização do negro LGBT por uma sociedade eurocêntrica e heteronormativa. É preciso que o discurso escolar sobre sexualidade vá além dos parâmetros biológicos e investigue e discuta as causas da influência de fatores étnico-raciais na afirmação e reconhecimento de gêneros e identidades e os efeitos que as relações étnico-raciais produzem sobre pessoas jovens que não se enquadram nos padrões de sexualidade e beleza ditados pela sociedade hegemônica.

A escola cumpre a sua função social e política não somente na escolha da metodologia eficaz para a transmissão dos conhecimentos historicamente acumulados ou no preparo das novas gerações para serem inseridas na sociedade, mas também quando incentiva o tratamento igualitário, o respeito às diferenças, a superação dos preconceitos e da discriminação existentes na sociedade. A instituição escolar não modifica por si só o imaginário e as representações coletivas negativas que se construíram sobre os ditos "diferentes" em nossa sociedade, mas ela ocupa um lugar de destaque na medida que pode promover a superação do preconceito, fazendo uso de um trabalho sistemático e crítico na formação de valores de cada aluno (ORTIZ, 2005).

Os livros didáticos não apresentam a preocupção em dar visibilidade necessária aos indivíduos pertencentes a etnias que não sejam de grupos brancos. Muitos jovens negros não se veem representados no ambiente e escolar e o problema se agrava quando o mesmo faz parte de grupos que apresentam orientações sexuais fora dos ditos padrões “normais". Se o indivíduo além de homossexual for negro, o problema é ainda maior, pois estará transitando em dois ambientes de preconceito e isso pode leva-lo à evasão, problemas de não aceitação com sua própria identidade, baixa autoestima, dentre outros.

\subsection{As faces do preconceito na escola}

Apresenta-se respostas de um questionário disponível em uma plataforma digital cerca do preconceito na escola. Em relação ao envolviento em discriminação observa-se 
que a maioria já esteve envolvido com esse violência.
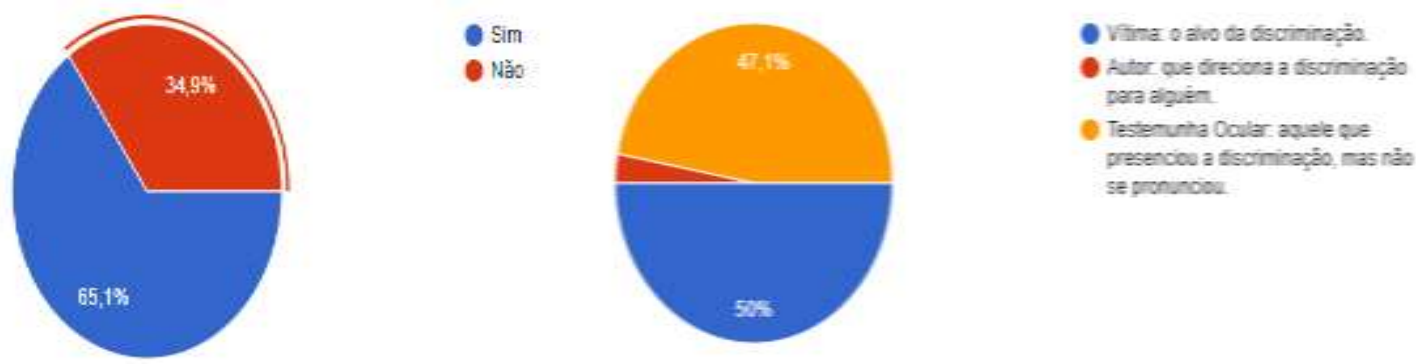

Gráfico: Envolvimento com a discriminação contra jovens negros gays.

O heterossexismo e a homofobia fazem parte do processo de controle e vigilância da conduta sexual e das expressões das identidades de gênero e muitas vezes também das identidades raciais. Sendo claramente mais difícil a convivência escolar para os alunos que transitam entre os mundos de duas minorias, como é o caso dos estudantes negros LGBT's.

Pessoas identificadas como dissonantes em relação ás normas de gênero e à matriz heterossexual serão postas sob a mira preferencial de uma pedagogia da sexualidade (LOURO, 1999) geralmente traduzida em insultos por meio de piadas, ridicularizações, brincadeiras, jogos, apelidos, insinuações, expressões desqualificantes e desumanizantes. Tratamentos preconceituosos, medidas discriminatórias, ofensas, constrangimentos, ameaças e agressões físicas ou verbais que tem sido um constante na rotina escolar de muitas pessoas.

O gênero é considerado nas escolas brasileiras de uma forma dicotômica que delimita as diferenças entre os sexos de forma singularizada (homem e mulher). No que tange à sexualidade, essa suposição implica uma visão heterossexual das relações entre os sexos. Masculinidades e feminilidades são reduzidas ás diferenças anatômicas, ao sexo biológico, desconsiderando a necessidade e o reconhecimento de outras formas de expressão da sexualidade além da heterossexual. Além disso, etnia, classe social e outros marcadores sociais, são desconsiderados nesta lógica dicotômica (GARCIA, SILVA, 2011).

Segundo Seffner (2011), os programas escolares foram pensados para alunos de classe média urbana, brancos, católicos, em geral do sexo masculino, e certamente heterossexuais. Se a escola não fizer a diferença na vida dos que não se enquadram nestes padrões para que os mesmo se sintam incluídos, ela estará estimulando sua evasão. Os

Educação, Psicologia e Interfaces, Volume 2, Número 2, p. 86-96, Maio/Agosto, 2018. 
Jovens negros lgbt's no ambiente escolar: como trabalhar a sexualidade nas escolas na perspectiva das relações étnico-raciais?

relatos da dessa pesquisa apontam nesse sentido,

Muitos jovens chamando um rapaz de gay porque ele era um rapaz com trejeitos femininos e na concepção deles o negro tem que ser másculo, mais até que o branco. Um preconceito racial, sexual, uma verdadeira cultura do machismo.

Eu não fui participante ativo, porém não ajudei o jovem, deixando que acontecesse todo o processo. $O$ menino saiu da escola pela discriminação e eu não fiz nada em relação a isso (DADOS DA PESQUISA, 2018).

Assim, na escola observa-se processo em que mantém as hierarquizações criadas com base na ideia de masculino e feminino. Até mesmo nos intrumentos oficiais e muitas vezes postos de maneira subliminar com atividades que segregam ou não, reforça as cobranças em tornos dos sujeitos para que os mesmos se enquadrem em determinados papéis ditos "normais".

Devido a este reforço de cobranças muitas identidades sexuais são estigmatizadas por por preconceitos, como por exemplo gays, lésbicas, bissexuais, travestis e transexuais e a escola pode acabar excluindo aqueles que não se adaptam aos comportamentos heteronormativos. Em relação a isso cabe descrever as respostas do questionamento: "os (as) professores(as) e administradores da escola onde você estuda (estudou) intervêm/interviam em casos de discriminação contra negros e gays ou qualquer outra forma manifesta de discriminação?"

Não, nunca vi ninguém ir para a secretaria por esses motivos.

Geralmente não estão preparados para lidar com essas situações.

Tratavam como brigas entre colegas, e não como casos de discriminação ou bullying (DADOS DA PESQUISA, 2018).

Frente a essas respostas, é primordial considerer que a sexualidade vista sob perspectiva étnico-racial vai além dos fenômenos puramente biológicos e busca abordar aspectos sócio-culturais para que seja feita uma análise do comportamento de professores e outros atores do processo educacional no que se refere á perpetuação e o reforço de preconceitos. O ambiente escolar deve promover a reflexão sobre sexualidade e estimular o questionamento de estereótipos de inferioridade étnico-racial valorizando o respeito à diversidade no ambiente escolar para que jovens como os negros LGBT's não se sintam excluídos e inferiorizados no ambiente onde deveriam ter reforçado o seu senso de pertencimento social e respeito.

A escola possui um arsenal que regula não só a sexualidade, mas também o 
gênero. As disposições heteronormativas voltam-se a naturalizar, impor, sancionar e legitimar um única sequência sexo-gênero-sexualidade: a centrada na heterossexualidade e rigorosamente regulada pelas normas de gênero, as quais, fundamentadas na ideologia do "dimorfismo sexual", agem com estruturadoras de relações sociais e produtoras de subjetividades (BUTLER, 2003).

Os resultado obtidos através da análise das referências e das respostas ao questionário digital nos permitem inferir que jovens já participaram de alguma forma de situação de discriminação, seja como vítima, autor e testemunha, porém muitos não interferem ou não sabem como procurar ajuda. Pode-se observer também há relatos em relação ao despreparo de professores e comunidade escolar para lidarem com situações de preconceito e exclusão.

Educadores que busquem abordar os temas de gênero e sexualidade na escola, em articulação com os estudos de relações étnico-raciais, devem se preparar para discutir os temas relacionados á sexualidade e o estereótipos que reforçam o preconceito e a exclusão no ambiente edcuacional, ja que as polêmicas que envolvem estes assuntos são grandes. Esta é uma tarefa mais do que necessária de ser feita pela escola nos dias atuais.

Antes de tudo deve-se ampliar a compreensão dos conceitos de gênero, sexualidade, pedagogias do gênero e da sexualidade para que através do conhecimento os próprios jovens possam se tornar agentes disseminadores da ideias de respeito à diversidade. O passo seguinte é analisar a articulação entre as questões de gênero e sexualidade na escola e o campo das relações étnico-raciais para que o conhecimento e respeito às etnias e ás diversas formas de ser e estar no mundo possam se tornar a base da convivência escolar entre os jovens.

\section{CONSIDERAÇÕES FINAIS}

Esse artigo descreveu sobre a sexualidade no ambiente escolar e propor uma reflexão, com o intuito de conscientizar educadores, a respeito do tema da sexualidade na perspectiva das relações étnico-raciais/lésbicas, gays, bissexuais, travestis transexuais ou trensgênicos (LGBT's). Foi possível identificar através do referencial teórico levando que há uma necessidade de discussão com professores sobre o tema em questão, assim como que também existem muitos materiais educativos que possam nortear professores no trabalho envolvendo a sexualidade na perspectiva das relações étnico-raciais.

Educação, Psicologia e Interfaces, Volume 2, Número 2, p. 86-96, Maio/Agosto, 2018. 
Jovens negros lgbt's no ambiente escolar: como trabalhar a sexualidade nas escolas na perspectiva das relações étnico-raciais?

É necessário que os materiais elaborados tenham um impacto no ensino da sexualidade sob a perspectiva das relações étnico-raciais e que o mesmo seja disponibilizado para fomenter a discussão no ambiente escolar. A conscientização dos educadores com a ampliação de conceitos como os de gênero e sexualidade e relações étnico-raciais irá refletir no trabalho com os alunos e pode resultar em uma melhor inclusão de discentes que não se enquadram nos abordados papéis definidos socialmente como aceitáveis, evitando assim a evasão e reforçando a ideia de pertencimento destes jovens ao ambiente escolar.

\section{REFERÊNCIAS BIBLIOGRÁFICAS}

AD JUNIOR: Moonglight e solidão do negro gay. Disponível em https://www.youtube.com/watch?v=tMJoQJvOLNY

BUTLER, Judith. Cuerpos que importam. Buenos Aires: Paidós, 2002.

Canal Grupo dos Cinco. Como é ser negro e gay no Brasil. Disponível em: https://www.youtube.com/watch?v=E86P8Hj9d4Q.

Canal Papo de Preta. Homem, negro, gay. Vamos Papear! Disponível em https://www.youtube.com/watch?v=hyJMV6rhVxI

GARCIA, Cláudia; SILVA, Rosimeri Aquino da. A escola e as relações de gênero e de sexualidade na atualidade. In: SILVA, Fabiane Ferreira da; MELLO, Elena Maria Billig (Orgs.). Corpos, gêneros, sexualidades e relações étnico-raciais na educação [recurso eletrônico]. Uruguaiana, RS: UNIPAMPA, 2011.

GOELLNER, Silvana V. A cultura fitness e a estética do comedimento: as mulheres, seus corpos e aparências. In: STEVENS, Cristina M. T.; SWAIN, Tânia N. (Orgs.). A construção dos corpos. Perspectivas feministas. Florianópolis: Editora Mulheres, 2008 .

LOURO, Guacira Lopes (Org.). O Corpo educado: pedagogias da sexualidade. Belo Horizonte: Autêntica, 1999.

LOURO, Guacira Lopes Corpo, Escola e Identidade. Educação \& Realidade, Porto Alegre, v. 25, n. 2, p. 59-75, jul./dez. 2000.

LOURO, Guacira Lopes. Gênero, Sexualidade e Educação: uma perspectiva pósestruturalista. 10. ed. Petrópoles: Vozes, 2008.

MOTTA, Jose Inacio Jardim. Sexualidades e políticas públicas: uma abordagem queer para tempos de crise democrática. Saúde debate, Rio de Janeiro, v. 40, n. spe, p. 7386, Dez. 2016.

ORTIZ, Cisele. Só não enxerga quem não quer: Racismo e preconceito na Educação 
Infantil. Revista Avisalá, no 23, nov. 2005.

ROSA, Waldemir. Homem Preto no Gueto: Um estudo sobre masculinidade no Rap brasileiro. Dissertação de Mestrado. Programa de Pós Graduação em Antropologia Social. Departamento de Antropologia. Universidade de Brasília, 2006.

SEFFNER, Fernando. Escola para todos: mesmo para aqueles que manifestam diferenças em sexo e gênero? In: SILVA, Fabiane Ferreira da; MELLO, Elena Maria Billig (Orgs.). Corpos, gêneros, sexualidades e relações étnico-raciais na educação [recurso eletrônico]. Uruguaiana, RS: UNIPAMPA, 2011.

WEEKS, Jeffrey. O corpo e a sexualidade. In: LOURO, Guacira Lopes. O corpo educado: pedagogias da sexualidade. Belo Horizonte: Autêntica, 1999, p. 35-54.

\section{Credenciais do autor}

RODRIGUES, Hiram Campos Rodrigues. Mestrando do Programa de Programa de Pós - Graduação em Ensino e Relações Étnico-Raciais da Universidade Federal do Sul Baiana - UFSB, Câmpus Paulo Freire. E-mail: hiramcampos_45@hotmail.com

Endereço para correspondência: Hiram Campos Rodrigues. UFSB, Câmpus Paulo Freire-Teixeira de Freitas, Praça Joana Angélica, 250, Bairro - São José. Teixeira de Freitas - BA, CEP 45988-058, Fone: (73) 3291-2089/3292-5834.

Como citar este artigo (Formato ABNT): RODRIGUES, H.C. Jovens negros LGBT's no ambiente escolar: como trabalhar a sexualidade nas escolas na perspectiva das relações étnico-raciais? Educação, Psicologia e Interfaces, v. 2, n. 2 p. 86-96, 2018. DOI: https://doi.org/10.37444/issn-2594-5343.v2i2.65

Recebido: 19/02/2018.

Aceito: 20/04/2018. 